\title{
Microstructural Changes in Ni-Al-Cr-Based Heat-Resistant Alloy with Re Addition
}

\author{
Nina A. Koneva ${ }^{1}$, Elena L. Nikonenko ${ }^{1}$, Alisa V. Nikonenko ${ }^{2}$ and Natalya A. Popova ${ }^{1, *}$ \\ 1 Department of Physics, Tomsk State University of Architecture and Building, 2, Solyanaya Sq., \\ 634003 Tomsk, Russia; koneva@tsuab.ru (N.A.K.); vilatomsk@mail.ru (E.L.N.) \\ 2 Department of Physics, Tomsk State University of Control Systems and Radioelectronics, 40, prospect Lenina, \\ 634050 Tomsk, Russia; aliska-nik@mail.ru \\ * Correspondence: natalya-popova-44@mail.ru
}

Citation: Koneva, N.A.; Nikonenko, E.L.; Nikonenko, A.V.; Popova, N.A. Microstructural Changes in Ni-Al-Cr-Based Heat-Resistant Alloy with Re Addition. Crystals 2021, 11, 89. https://doi.org/10.3390/cryst 11020089

Academic Editor: Wojciech Polkowski Received: 29 December 2020

Accepted: 18 January 2021

Published: 21 January 2021

Publisher's Note: MDPI stays neutral with regard to jurisdictional claims in published maps and institutional affiliations.

Copyright: (c) 2021 by the authors. Licensee MDPI, Basel, Switzerland. This article is an open access article distributed under the terms and conditions of the Creative Commons Attribution (CC BY) license (https:// creativecommons.org/licenses/by/ $4.0 /)$.

\begin{abstract}
This paper presents scanning and transmission electron microscope investigations of the structure, phase composition, and morphology of a heat-resistant alloy modified by thermal treatment and additionally alloyed by rhenium. The rhenium alloy was obtained by using the directional crystallization technique. The structural investigations were carried out for two states of the alloy, i.e., (1) original (after the directional crystallization); (2) after the directional crystallization with $1150{ }^{\circ} \mathrm{C}$ annealing for $1 \mathrm{~h}$ and $1100{ }^{\circ} \mathrm{C}$ annealing for $480 \mathrm{~h}$. It is shown that fcc-based $\gamma$ - and $\gamma^{\prime}$-phases are primary in all states of the alloy. The $\gamma^{\prime}$-phase has an $\mathrm{L} 1_{2}$ structure, while $\gamma$-phase is a disordered phase. It was found that after directed crystallization, the volume fraction of the $\gamma^{\prime}$ phase is $\sim 85 \%$, the fraction of the $\gamma$-phase is less than $10 \%$. Annealing leads to an increase in the $\gamma^{\prime}$ - phase up to $90 \%$, the proportion of the $\gamma$-phase practically does not change. Rhenium is a phase-formation element. The investigations show that high-temperature annealing modifies the structural and phase conditions of the heat-resistant alloy.
\end{abstract}

Keywords: aluminum; nickel; superalloys; $\gamma^{\prime}$ - and $\gamma$-phases; close-packed phases; rhenium

\section{Introduction}

The global political processes of the last century have triggered the emergence of materials used in the manufacture of the engine-related parts of jet aircrafts, i.e., superalloys. Further enhancement of the properties of materials operating under high temperatures has enabled them to increase their operating temperatures and operating voltages by improving the production processes and changing the chemical compositions of superalloys. Progress in the development of such alloys has made it possible to create modern jet engines with an even higher ratio of the developed thrust to the dead weight of the engine. Superalloys play a vital role in industrial gas turbines, coal refineries, and other installations where high temperatures and highly corrosive environments operate [1-3].

The success of modern technology is largely driven by the creation and application of metallic materials with the necessary service properties. The level of the requirements for these materials is constantly growing due to the new problems that arise when creating new equipment, particularly when operating under extreme conditions, such as high velocities, high temperatures, etc. The search for metallic materials that can operate in these extreme conditions is constantly ongoing [4]. One of the promising directions is the development of superalloys containing intermetallic phases. Some examples of these superalloys are those based on a mixture of $\gamma^{\prime}$ - and $\gamma$-phases [1-6], where the $\gamma$-phase is a disordered fcc solid solution based on, e.g., nickel and aluminum, while the $\gamma^{\prime}$-phase (in this case, $\mathrm{Ni}_{3} \mathrm{Al}$ ) is an ordered structure with an $\mathrm{L1}_{2}$ superstructure [7-9]. Currently, superalloys are often created on the basis of an alloy of nickel and aluminum alloyed with various refractory elements. In these modern superalloys, the $\gamma^{\prime}$-phase is the primary one. For this reason, it is largely responsible for the formation of the superalloy properties. 
With the development and creation of superalloys, the proportion of the $\gamma$-phase in the superalloy decreases, while the proportion of the $\gamma^{\prime}$-phase increases (up to $90 \%$ or more). In real nickel-based superalloys, the composition of which has multiple components, along with $\mathrm{Ni}$ and $\mathrm{Al}$, there are atoms of other elements, such as $\mathrm{Ti}, \mathrm{Cr}, \mathrm{Co}, \mathrm{Mo}, \mathrm{W}, \mathrm{Ta}, \mathrm{Nb}, \mathrm{Hf}$, and $\operatorname{Re}[1,2,10-16]$. Alloying with Re increases the operating temperature and entails the appearance of topologically close-packed phases (TCP-phases) inside the material, which are called Frank-Kasper phases. These phases can have a complex effect on the structure and properties of superalloys [17-20].

It has also been established that Re is mainly localized in the $\gamma$-phase [21-23]. When concentrated in solid $\gamma$-solution, Re reduces the velocity of diffusion processes under working temperatures, and thus increases thermal stability of $\gamma$-matrix. Thus, with an increase in Re content, the long-term strength of heat-resistant alloys grows [21]. Apart from the increase in strength properties, a larger content of Re also results in increased numbers and sizes of $\gamma$-phase interlayers, which significantly reduce the coarsening kinetics of $\gamma^{\prime}$-phase quasi-cuboids [21,22]. Moreover, Refs. [21-23] revealed inhomogeneities in the spatial distribution of Re: Areas enriched with Re are localized close to the border of the $\gamma-/ \gamma^{\prime}$-phases on the side of the $\gamma$-phase $[21,22]$.

Thus, superalloys, their structures, and their mechanical properties under high temperatures and under low temperatures, as well as their stability in operating conditions, represent one of the greatest achievements in the physics of alloys nowadays. Their creation and the need to obtain high properties require studying the structure and properties of solid solutions, ordered phases, and intermetallic compounds, constructing numerous equilibrium diagrams, solving high-temperature strength problems, studying creep resistance, and solving numerous other problems. Since the morphology of the $\gamma^{\prime}$-phase can have a decisive influence on the mechanical properties of the superalloy, it seems important to study the structures of various superalloys in detail using structural research methods, which, along with the study of the phase composition of multicomponent superalloys, allow detailed study of the morphology of the $\gamma^{\prime}$-phase. The studies carried out within this work are aimed at solving some of the above-mentioned problems.

The aim of this work was to qualitatively and quantitatively study the structure, phase composition, and phase morphology of a complexly alloyed heat-resistant alloy additionally alloyed with Re both in the initial state and after heat treatment.

\section{Materials and Methods}

The study of the structure of the alloy was carried out in two states: (1) the initial stateafter directional crystallization (DC); (2) DC + annealing at a temperature of $\mathrm{T}=1150{ }^{\circ} \mathrm{C}$ for $1 \mathrm{~h}+$ annealing at the temperature of $\mathrm{T}=1100{ }^{\circ} \mathrm{C}$ for $480 \mathrm{~h}$. All states of the alloy had a monocrystalline structure with the [001] orientation.

The basic elements of the alloy were: Ni: $\sim 70$ at. $\%, \mathrm{Al}: \sim 17$ at. $\%$, and $\mathrm{Cr}: \sim 5$ at. $\%$. The alloying elements were Mo: 3 at. $\%$, W: 1.2 at. $\%$, Ti: 1.3 at. $\%$, Co: 2 at. $\%$, C: 0.1 at. $\%$, and Re: 0.4 at.\%. The chemical composition was determined by $\mathrm{X}$-ray fluorescence analysis.

Three methods were used in the present work: (1) transmission electron microscopy (TEM) (transmission electron microscope EM-125), (2) scanning electron microscopy (SEM) (electron microscope QUANTA 200 3D FEI), and 3) a method of X-ray diffraction analysis (DRON-7 diffractometer with 20-920 range for angles).

Using the SEM method, the following structural parameters were identified: the shapes and sizes of large particles of the $\gamma^{\prime}$ phase $(\geq 1 \mu \mathrm{m})$ and secondary phases, their relative positions, and their volume fractions. TEM images of the fine structures of the materials were used: firstly, to classify the structures; secondly, to identify phases and determine the size and volume fraction of the main $\gamma$ - and $\gamma^{\prime}$-phases and precipitates of the secondary phases $(\leq 1 \mu \mathrm{m})$ [24], as well as their localization sites; thirdly, to determine the scalar dislocation density $(\rho)$. In the case of X-ray structural analysis, the images of samples were taken at room temperature on an X-ray diffraction meter. The positions of 
the diffraction maxima that were clearly related to the unit cell size were used to calculate the crystal lattice parameters of the present phases.

The average sizes of structural elements (phases) and the scalar dislocation density were measured from the corresponding micrographs using the secant method [25]. The data obtained were processed statistically. Phase analysis was carried out on the basis of data obtained via transmission electron microscopy from the interpretation of the corresponding microdiffraction patterns, observations in the bright and dark fields of high resolution, and the results of the X-ray structural analysis [26].

\section{Results and Discussion}

\subsection{Phase Composition}

The electron microscopy method showed the presence of a number of phases in different states of the alloy, the qualitative and quantitative composition of which depends on the heat treatment (Table 1).

Table 1. Phase composition and quantitative properties of phases.

\begin{tabular}{|c|c|c|c|c|c|}
\hline \multirow{2}{*}{ Phases } & \multirow{2}{*}{ Crystal Lattice Type } & \multirow{2}{*}{ Spatial Group } & \multirow{2}{*}{$\begin{array}{l}\text { Parameter of Crystal } \\
\text { Lattice, } \mathbf{n m}\end{array}$} & \multicolumn{2}{|c|}{ Volume Fraction of Phases $( \pm 1), \%$} \\
\hline & & & & After DC & After DC + Annealing \\
\hline$\gamma^{\prime}$ & Cubic & $\mathrm{Pm} 3 \mathrm{~m}$ & $a=0.3568-0.3575$ & 85.6 & 90.0 \\
\hline$\gamma$ & Cubic & $\mathrm{Fm} 3 \mathrm{~m}$ & $a=0.3569$ & 8.0 & 9.0 \\
\hline$\beta$ & Cubic & $\operatorname{Pm} \overline{3} \mathrm{~m}$ & $a=0.288$ & 5.0 & 0 \\
\hline$x$ & Cubic & $I \overline{4} 3 \mathrm{~m}$ & $a=0.957-0.960$ & 1.4 & 0 \\
\hline$\sigma$ & Tetragon & $\mathrm{P} 4_{2} / \mathrm{mnm}$ & $\begin{array}{l}a=0.910-0.960 \\
c=0.475-0.499\end{array}$ & 0 & 1.0 \\
\hline
\end{tabular}

The phases observed in a superalloy can be classified into primary and secondary phases. This classification is based on the volume fractions of the phases, their roles in the alloy, and stationary or single presence. As seen in Table 1 , the primary phases are $\gamma^{\prime}$ - and $\gamma$-phases. They form the basic structure of the alloy in almost all superalloys [1,2]. The $\gamma^{\prime}$-phase is an ordered solid solution with the $\mathrm{L}_{2}$ superstructure (based on $\mathrm{Ni}_{3} \mathrm{Al}$ ); the $\gamma$-phase is an fcc-disordered solid solution based on nickel [1,2]. In the alloy under study, these phases are present in the form of $\gamma^{\prime}$-phase quasi-cuboids [20] separated by $\gamma$-phase interlayers. The rest of the phases are secondary. Different secondary phases are present depending on the state of the alloy. The types and volume fractions of all present phases regardless of their state are given in Table 1 . The deviation in determining the volume fractions of phases is $\pm 1 \%$.

As seen in Table 1, the volume fraction of the $\gamma$-phase is kept the same irrespective of the alloy state.

The secondary phases are phases $\beta, \chi$, and $\sigma$ (Table 1 ). The TEM studies showed that, under the symbol " $\beta$-phase", two phases can be present in the alloy: (1) $\beta$-NiAl with a crystal lattice parameter of $a=0.288 \mathrm{~nm}$, and (2) AlRe with the same crystal lattice parameter of $\mathrm{a}=0.288 \mathrm{~nm}$. Both of them have a $\mathrm{CsCl}$ structure, and both can transform into tetragonal phases of the $\mathrm{L}_{0}$ type [27]. These phases are mutually soluble, they can form solid solutions, and their presence on the sides of the $\mathrm{Ni}-\mathrm{Al}$ and $\mathrm{Al}-\mathrm{Re}$ triangle of the $\mathrm{Ni}-\mathrm{A}-\mathrm{Re}$ triple diagram means [28] that they can form a larger area by connecting these positions. Both phases (AlRe and $\beta$-NiAl) can be called the $\beta$-phase.

The next two phases, $\sigma$ and $\chi$ (see Table 1 ), refer to topologically close-packed phases or, in other words, to Frank-Kasper phases [17-20]. Their appearance is due to the presence of Re in the alloy. Indeed, the interaction of Re with Mo and W leads to the appearance of the $\sigma$ and $\chi$ phases: The $\sigma$-phase is formed as a result of solidification at high temperatures, and the $\chi$-phase is formed as a result of decomposition at lower temperatures or as a result of crystallization. In addition, the $\sigma$-phase arises as a result of the interaction of Re with Co, 
$\mathrm{Cr}, \mathrm{Ni}$, and $\mathrm{Al}$, and the $\mathrm{\chi}$-phase is formed due to the interaction with Mo and $\mathrm{W}$, as well as with $\mathrm{Co}$ and $\mathrm{Al}$.

\subsection{Phase Morphology}

It is known that the structure of superalloys is a mixture of $\left(\gamma+\gamma^{\prime}\right)$-phases. This mixture has a morphologically correct crystallographic orientation and forms a quasimonocrystalline structure. The presence of active phase-forming metals in the alloy complicates the structure of the superalloy and causes the appearance of areas with a damaged $\gamma-/ \gamma^{\prime}$-structure in them. In the investigated alloy, the phase-forming metal is mainly Re. The presence of Re contributes to the formation of a part of the $\beta$-phase, as well as to the complete formation of the $\sigma$ - and $\chi$-phases. The formation of these four phases seriously disturbs the structure of $\gamma / \gamma^{\prime}$ quasi-cuboids [20]. Research has shown that these phases are shaped like needles or plates. Since Re does not uniformly fill the entire volume of the alloy and is only present in local areas, then, in all states of the alloy, only a part of the volume of $\gamma / \gamma^{\prime}$ quasi-cuboids was damaged.

The conducted studies enabled presentation of the schemes of the alloy samples under study. They are given in Figure 1.

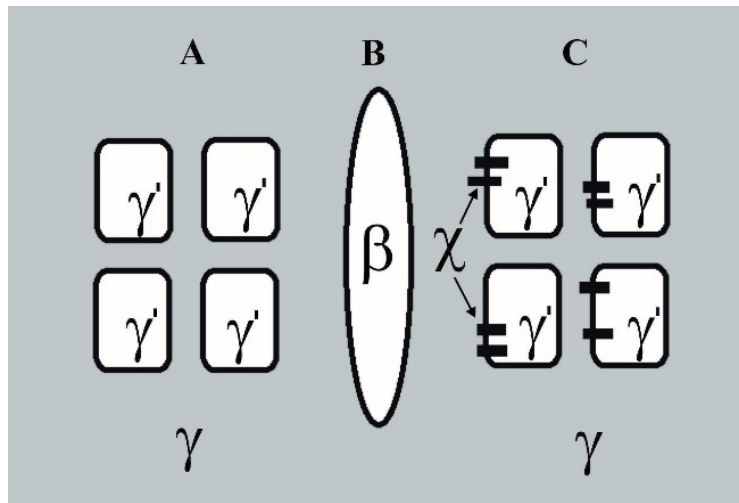

(a)

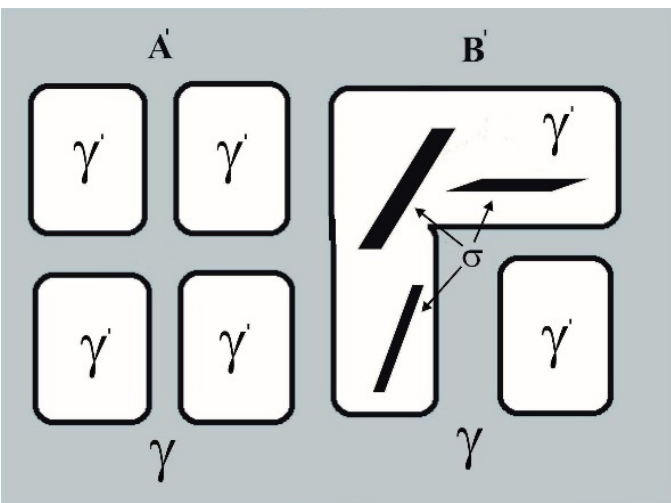

(b)

Figure 1. Schematic representation of the structure of the alloy: (a) the structure of the alloy in the initial state (after directional crystallization (DC)); (b) structure of the alloy after DC and annealing.

Let us comment on these figures.

A schematic representation of the structure of the alloy after DC (initial state) is shown in Figure 1a. It is clearly seen that the alloy contains three different morphological phase states, i.e., " $\mathrm{A}$ ", " $\mathrm{B}$ ", and " $\mathrm{C}$ ". The volume fractions of these states, their phase compositions, and the sizes of the quasi-cuboids of the $\gamma^{\prime}$-phase are given in Table 2.

Table 2. Structural phase states of the alloy and their quantitative data after DC.

\begin{tabular}{ccccc}
\hline The State & $\begin{array}{c}\text { Volume Fraction } \\
\text { of the State, } \%\end{array}$ & Phase Composition & The Size of Quasi-Cuboids, nm & Particle Size of $\boldsymbol{\chi}$-Phase, $\mathbf{n m}$ \\
\hline A & 65 & $\gamma^{\prime}+\gamma$ & $320 \times 440$ & - \\
\hline B & 5 & $\beta$ & $320 \times 440$ & - \\
\hline C & 30 & $\gamma^{\prime}+\gamma+\chi$ & $30 \times 240$ \\
\hline
\end{tabular}

It is clearly seen from the diagram in Figure 1 a that state " $\mathrm{A}$ " is an ideal structure $\left(\gamma+\gamma^{\prime}\right)$ with slightly anisotropic distortion. Its TEM image is shown in Figure 2, which, along with the bright-field image (Figure 2a), indicates a microdiffraction pattern (Figure $2 b$ ). Additionally shown are the dark-field images obtained in the superstructure reflection [012] of the $\gamma^{\prime}$-phase (Figure 2c) and in the reflection [311], which, due to the parallelism of the crystal lattices of the $\gamma^{\prime}$ - and $\gamma$-phases [1,2], is simultaneously the main 
reflection for the $\gamma^{\prime}$ - and $\gamma$-phases (Figure 2d). It is these reflections that make it possible to separate the $\gamma^{\prime}$ - and $\gamma$-phases: the first reflection is the quasi-cuboids of the $\gamma^{\prime}$-phase, and the second is the interlayers of the $\gamma$-phase. That is why, in Figure 2c, only the structure of the quasi-cuboids of the $\gamma^{\prime}$-phase is visible, and in Figure $2 \mathrm{~d}$, both the structure of the quasi-cuboids of the $\gamma^{\prime}$-phase and the interlayer of the $\gamma$-phase are visible.

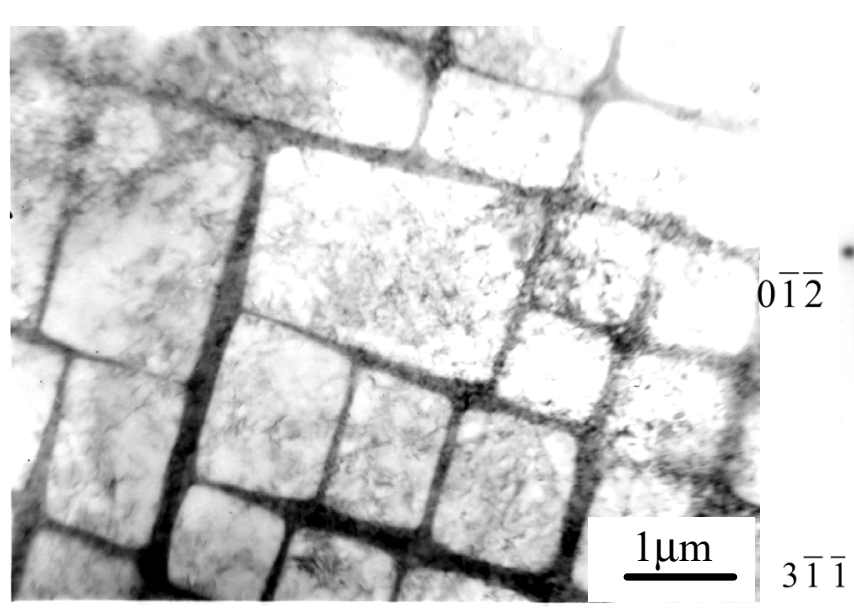

(a)

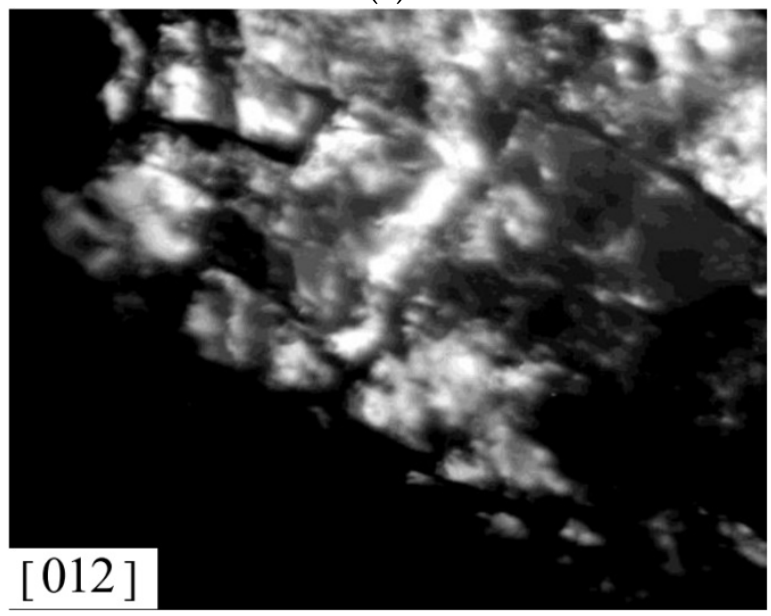

(c)

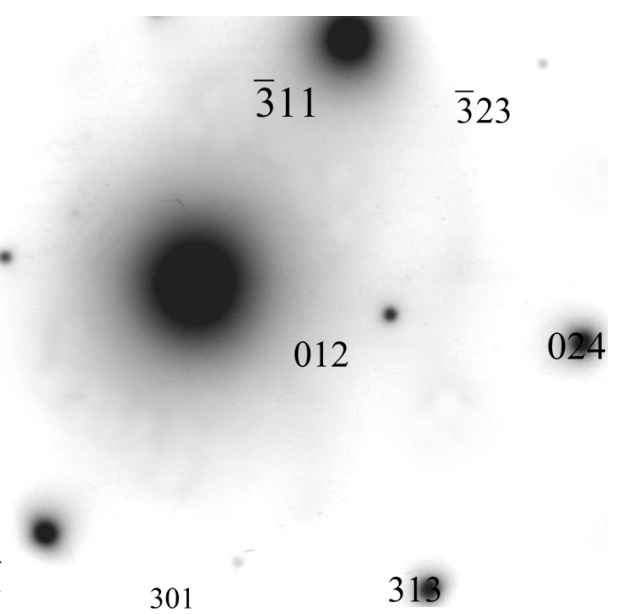

(b)

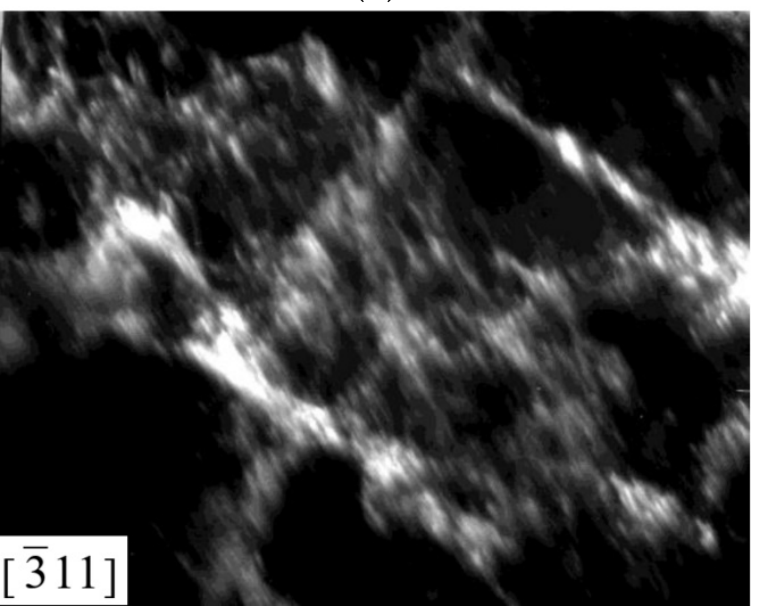

(d)

Figure 2. Electron microscopic image of a quasi-cuboid structure $\left(\gamma^{\prime}+\gamma\right)$ in the alloy after DC (structural phase state "A"): (a) bright-field image; (b) indicated microdiffraction pattern; (c,d) dark-field images obtained, respectively, in the superstructure reflection [012] and the main reflection [311].

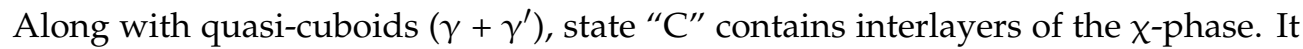
was found that, in the " $\mathrm{C}$ " state, the quasi-cuboids of the $\gamma^{\prime}$-phase are also anisotropic, and the volume fraction of the $\gamma$-phase is close to $5 \%$. It was found that, first, the $\chi$-phase interlayers can be localized in both the $\gamma^{\prime}$ - and $\gamma$-phases and, secondly, the crystallographic orientation of the $\chi$-phase interlayers, like the orientation of the $\gamma$-phase interlayers, is parallel to the cubic directions of $\gamma^{\prime}$-phases. The proof of the second statement is Figure 3 , which shows an image of the structural phase state " $\mathrm{C}$ ". Figure 3 shows the parallelism of the $\chi$-phase interlayers and the $\gamma$-phase interlayers. Both phases have cubic crystal lattices; however, the differences in the parameters of the crystal lattices make them have some crystallographic misorientation. 


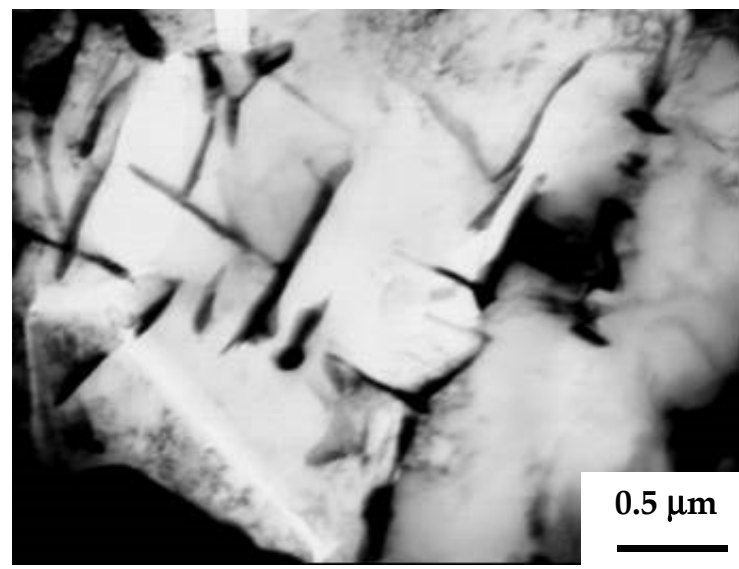

(a)

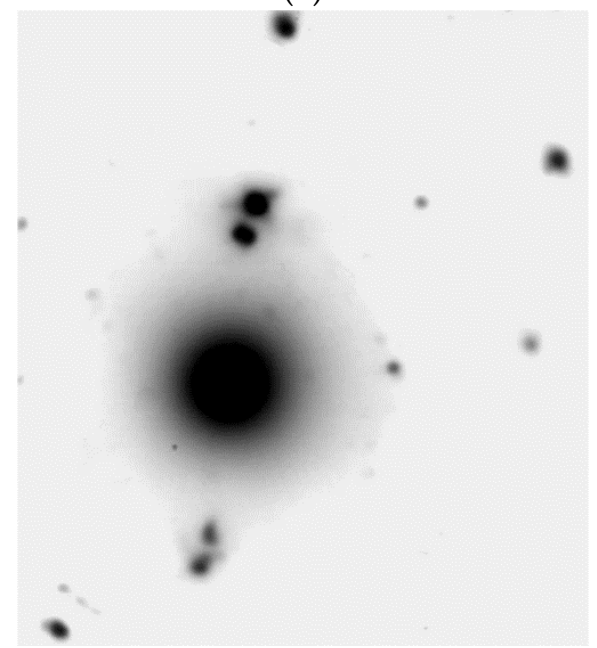

(c)

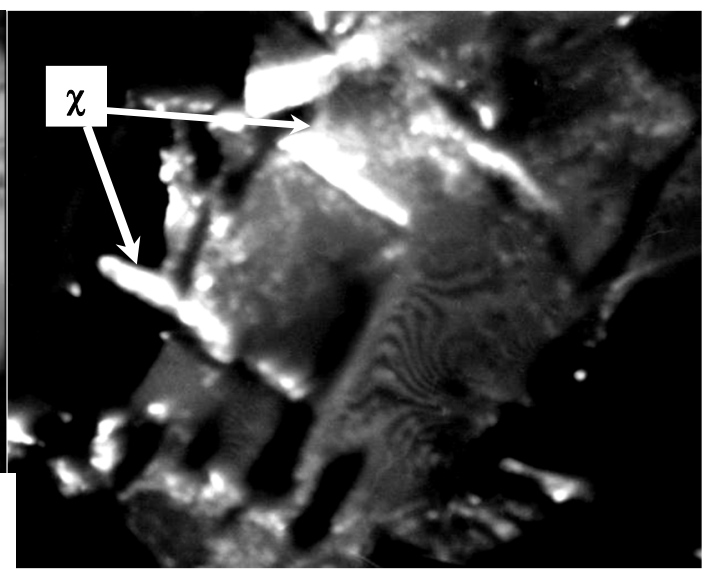

(b)

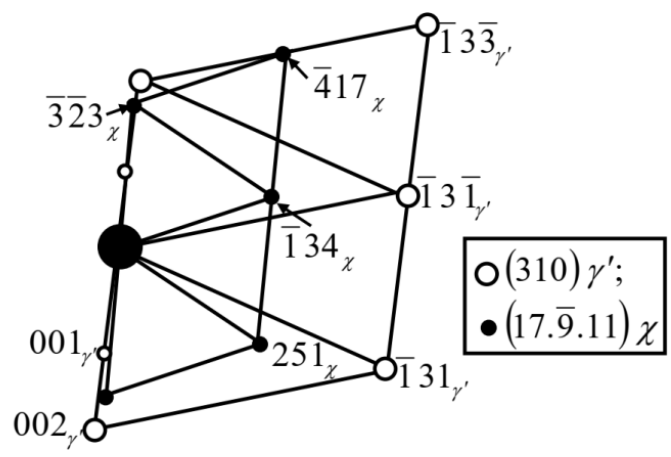

(d)

Figure 3. Electron microscopic image of the structural phase state " $\mathrm{C}$ " in the alloy after DC: (a) bright-field image; (b) dark-field image obtained in the reflection $[\overline{32} 3]_{\chi} ;(\mathbf{c})$ microdiffraction pattern; $(\mathbf{d})$ its indicated scheme.

The point is that the parameters of the crystal lattices of these phases are noticeably different $\left(a_{\gamma}=0.3569 \mathrm{~nm} ; a_{\chi}=0.9570 \mathrm{~nm}\right)$. Figure 3c shows that the [002] direction, which is simultaneously the main direction for the $\gamma^{\prime}$ - and $\gamma$-phases, is almost parallel to the $[32 \overline{3}] \chi$ direction. In other words, despite the difference in the crystal lattice parameters of these phases, the tendency toward a minimum of elastic energy led to the formation of a crystallographic orientation with the above-mentioned orientation ratio and parallelism of the $\chi$ - and $\gamma$-phase interlayers. In this case, there are no elastic stress fields. This is indicated by the absence of the structure of bending-torsion extinction contours in the electron microscopic images [20]. Thus, the $\gamma$ - and $\gamma^{\prime}$-phases are in almost coherent and stress-free contact with the $\chi$-phase.

State " $\mathrm{B}$ " is distinguished by a completely damaged structure of quasi-cuboids. The entire volume of section " $\mathrm{B}$ " is occupied by a $\beta$-phase.

Consider the contact between the $\beta$-phase and the $\gamma-/ \gamma^{\prime}$-phase block (Figure 4 ).

The boundary between the block and the $\beta$-phase runs along the [011] direction of the $\gamma^{\prime}$-phase. The orientation ratio of the $\beta$-phase and $\gamma-/ \gamma^{\prime}$-phases is [110] $\beta$ II [111] $\gamma^{\prime}$. This is a typical ratio for the mutual phase transformation fcc $\rightarrow$ bcc, for example, in steels [19]. Significantly, the extinction contours of bending-torsion are not observed near the $\beta$ $\gamma / \gamma^{\prime}$ boundary (see Figure 4a). This means that the $\beta-, \gamma^{-}$, and $\gamma^{\prime}$-phases are coherently connected. The microdiffraction pattern shown in Figure $4 \mathrm{~b}$ characterizes the structure of the $\beta$-phase. The presence of diffuse strands connecting reflections may indicate a non- 
stoichiometric composition against the formula indicated above, as well as the presence of a micro-phase separation in it. That is why this phase disappears after annealing.

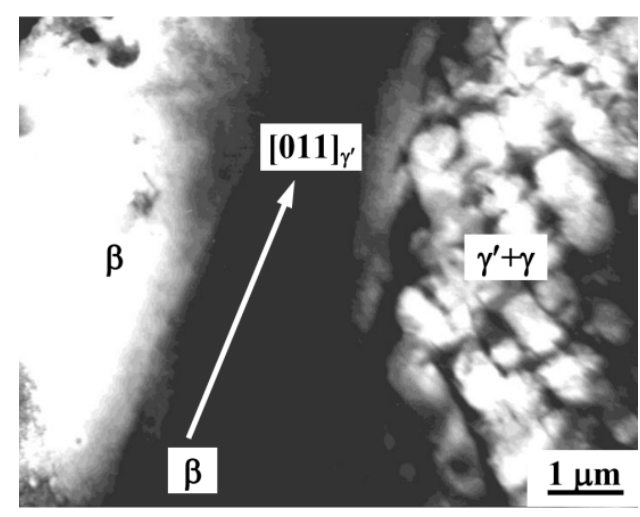

(a)

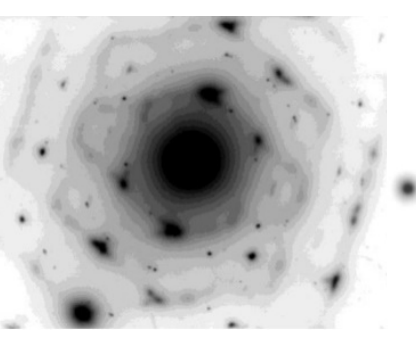

(b)

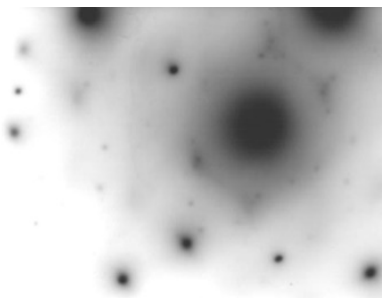

(c)

Figure 4. Electron microscopic image of the fine structure in the sample after DC: (a) junction of structural phase states " $A$ " $\left(\gamma^{\prime}+\gamma\right)$ and "B" $(\beta) ;(\mathbf{b})$ microdiffraction pattern obtained from state "B" (there are only reflections of the $\beta$-phase); (c) microdiffraction pattern obtained from state "A" (only reflections of the $\gamma-/ \gamma^{\prime}$-mixture are present).

The integral image of the alloy structure after DC, which was obtained with the SEM method at a lower magnification, is shown in Figure 5a. As seen in Figure 5a, most of the alloy's volume is represented by quasi-cuboids (solid and damaged), the contrast from which does not differ due to a relatively small increase. The separation by Re is clearly visible due to the precipitation of the $\beta$-phase, which is predominantly stabilized by this chemical element. Particles of the $\beta$-phase are also shown in Figure 5a.

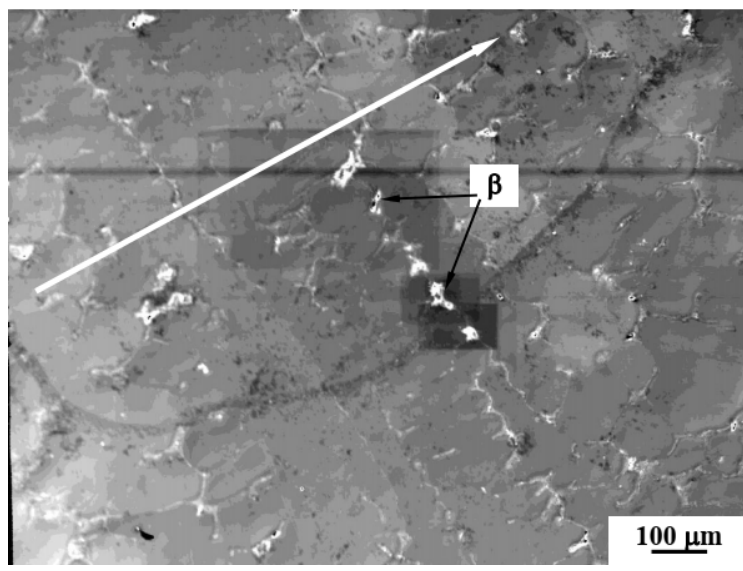

(a)

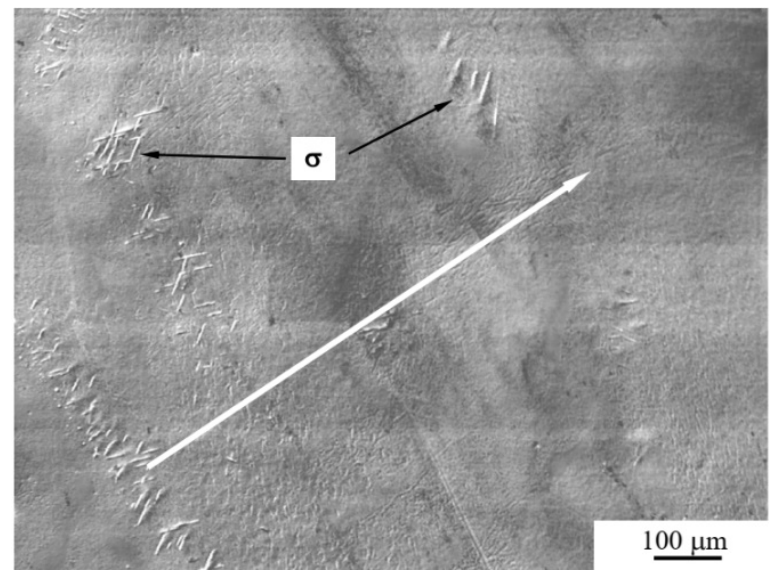

(b)

Figure 5. Scanning electron microscopy (SEM) images of the alloy structure: (a) image of the alloy after DC; (b) image of the alloy after DC and annealing. The black arrows in (a) mark examples of particles of the $\beta$-phase, and those in (b) mark the $\sigma$-phase; white arrows show the direction of periodicity.

Thus, concluding the description of the morphology and phase composition of the alloy after DC, we note that $95 \%$ of its volume consists of quasi-cuboids of $\gamma-/ \gamma^{\prime}$-phases; $65 \%$ of these are ideal quasi-cuboids and $30 \%$ are quasi-cuboids containing $x$-phase interlayers. Finally, $5 \%$ of the volume is occupied by the $\beta$-phase, the basis of which is the bcc-ordered ternary $\mathrm{NiAl}_{2}$ Re phase.

A schematic representation of the structure of the alloy after DC and annealing is shown in Figure 1b. As can be seen, the alloy consists of ideal quasi-cuboids-the volume fraction of which is $90 \%$ - and quasi-cuboids distorted by the presence of the $\sigma$-phase, the 
volume fraction of which is $10 \%$. Let us designate the corresponding structural phase states as " $\mathrm{A}$ " " and " $\mathrm{B}^{\prime \prime}$ ", the quantitative data of which are given in Table 3 .

Table 3. Structural phase states and quantitative data of the alloy after DC and annealing.

\begin{tabular}{ccccc}
\hline States & $\begin{array}{c}\text { Volume Fraction } \\
\text { of States, } \%\end{array}$ & Phase Composition & The Size of Quasi-Cuboids,nm & The Size of $\boldsymbol{\sigma}$-Phase Particles, nm \\
\hline $\mathrm{A}^{\prime}$ & 90 & $\gamma^{\prime}+\gamma$ & $1440 \times 1720$ & - \\
\hline $\mathrm{B}^{\prime}$ & 10 & $\gamma^{\prime}+\gamma+\sigma$ & $1440 \times 1720$ & $290 \times 4050$ \\
\hline
\end{tabular}

Electron microscopic images of the states " $\mathrm{A}^{\prime \prime}$ " and " $\mathrm{B}^{\prime \prime}$, , respectively, are shown in Figures 6 and 7.

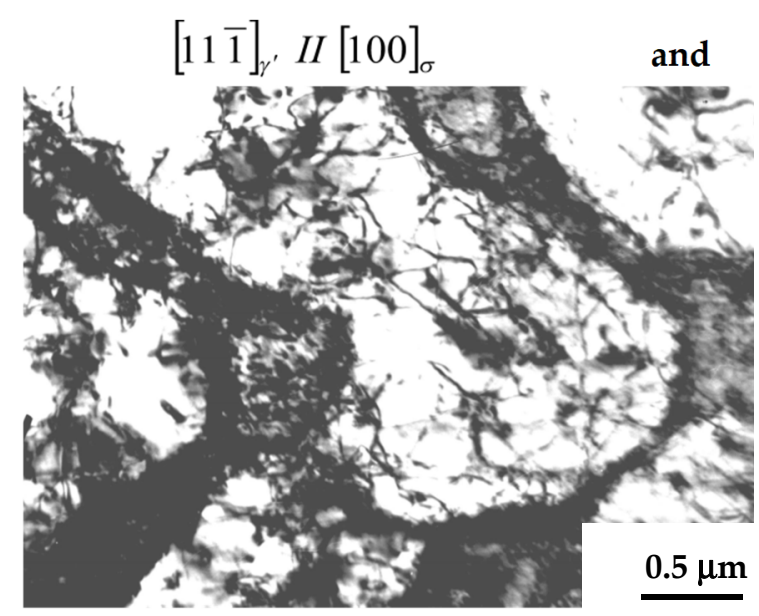

(a)

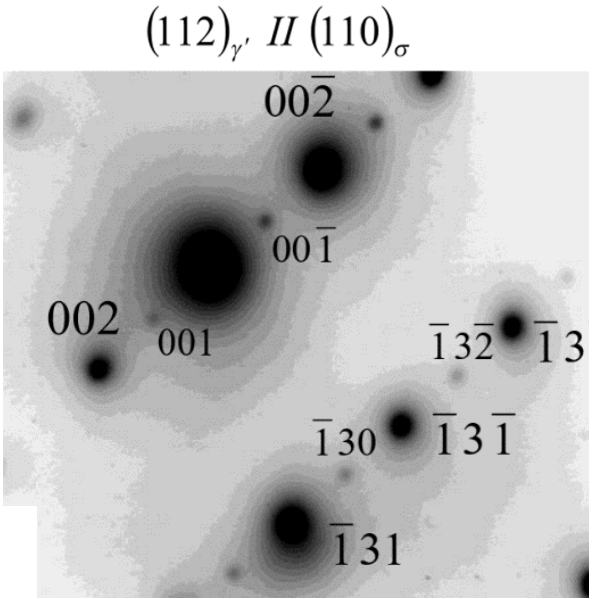

(b)

Figure 6. Electron microscopic image of a quasi-cuboid structure $\left(\gamma^{\prime}+\gamma\right)$ in the alloy after DC and annealing (structural phase state " $\mathrm{A}^{\prime \prime}$ "): (a) bright-field image; (b) in the indicated microdiffraction pattern, there are reflections belonging to the (310) plane of the $\gamma^{\prime}$-phase.

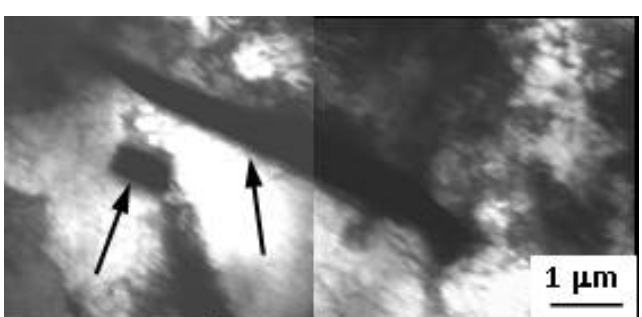

(a)

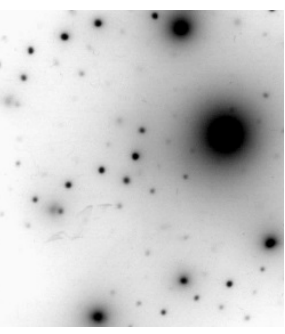

(b)

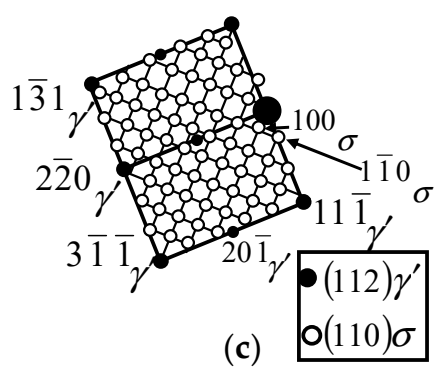

(c)

Figure 7. Electron microscopic image of the structural phase state " $\mathrm{B}^{\prime \prime}$ in the alloy after DC and subsequent annealing: (a) bright-field image (arrows indicate particles of the $\sigma$-phase); (b) microdiffraction pattern; (c) its diagram.

Figure 6 shows a TEM image of a quasi-cuboid structure $\left(\gamma^{\prime}+\gamma\right)$ that corresponds to the " $\mathrm{A}^{\prime \prime}$ " state (Figure 1b). This figure clearly shows the $\gamma^{\prime}$-phase cuboids separated by $\gamma$-phase interlayers.

Figure 7 shows the particles of the $\sigma$-phase, which have a plate-like shape and are located along the [011] and [001] directions of the $\gamma^{\prime}$-phase. The diffraction analysis in Figure 7 shows that the crystal lattices of the $\gamma^{\prime}$ - and $\sigma$-phases have coinciding directions and planes.

The contact between the $\gamma^{\prime}$ - and $\sigma$-phases occurs without noticeable distortions. This is evidenced by the absence of bending-torsion extinction contours in the structure. As can 
be seen from Figure 7, the structure of quasi-cuboids is damaged in the places of formation of the $\sigma$-phase.

If, after DC, the ideal quasi-cuboids account for $65 \%$ of the alloy's volume, then in the state after DC and subsequent annealing, they already make up $90 \%$.

Figure $5 \mathrm{~b}$ shows an SEM image of the alloy's structure after DC and annealing. The local distribution of particles of the $\sigma$-phase is clearly seen, and it alternates with the ideal structure of $\gamma-/ \gamma^{\prime}$-phases.

Therefore, the analysis of Figure $5 \mathrm{a}, \mathrm{b}$ indicates the presence of periodicity in the arrangement of spatial structures (structural phase states " $\mathrm{A}^{\prime}$, , $\mathrm{B}^{\prime}$, , “ $\mathrm{C}^{\prime \prime}$, " $\mathrm{A}^{\prime \prime \prime}$, , $\mathrm{B}^{\prime \prime \prime}$ ). Similar results were obtained in [22], where an inhomogeneous distribution of phases containing a large amount of Re was theoretically proved. It was noted that this non-uniform distribution has a wave-like nature. It has been stated that this inhomogeneity is caused by the heterogeneous Re distribution. In this work, this fact was confirmed experimentally and was called the "periodicity". The direction of periodicity is indicated by a long arrow in the images of the structure (Figure 5). The ideal state of the $\gamma-/ \gamma^{\prime}$-mixture and the strongly damaged one $\left(\gamma^{\prime}+\gamma+\right.$ secondary phases) alternate along it. The average width of each layer is given in Table 4.

Table 4. Quantitative data of the periodicity of the structure of the superalloy.

\begin{tabular}{|c|c|c|c|}
\hline The State of the Alloy & $\begin{array}{c}\text { The Width of Interlayers of Ideal } \\
\text { Structure }\left(\gamma^{\prime}+\gamma\right), \mu \mathrm{m}\end{array}$ & $\begin{array}{c}\text { The Width of Interlayers } \\
\text { with Secondary Phases, } \mu \mathrm{m}\end{array}$ & The Length of Periodicity, $\mu \mathrm{m}$ \\
\hline After DC & 120 & 10 & 130 \\
\hline After DC and annealing & 420 & 25 & 445 \\
\hline
\end{tabular}

In this case, in the alloy after DC, the main period length is occupied by an ideal structure $\left(\gamma^{\prime}+\gamma\right)$ that is $120 \mu \mathrm{m}$ wide, the structure with secondary phases is very local$10 \mu \mathrm{m}$. In turn, in the structure of the alloy after DC and subsequent annealing, the width of ideal interlayers is, on average, about 3.5 times greater than the corresponding width of the alloy after DC, and the width of interlayers with secondary phases is $\sim 2.5$ times greater. There is no doubt that the periodic structure of the superalloy with a suitable orientation should strengthen the material. In other words, there are reserves at the mesoscale for strengthening the superalloy material.

\subsection{Crystallographic Correspondence of the Primary and Secondary Phases in All States of the Superalloy and the Problem of the Long-Range Stress Field}

The complex phase composition of the superalloy under study is not its only feature. An important structural property is the concentration layer separation, which leads to a periodic structure and localization of secondary phases in the $\left(\gamma^{\prime}+\gamma\right)$ mixture. This is clearly seen in Figure 5. A detailed simultaneous electron microscopic and diffraction study of the structure of areas with secondary phases localized in the $\gamma^{\prime}$ - and $\gamma$-phases showed the absence of extinction contours and, thus, the absence of noticeable internal stresses. This behavior is due to the good crystallographic agreement between the crystal lattices of $\gamma / \gamma^{\prime}$ and the secondary phases, which is organized during the separation of these phases. The corresponding orientation ratios are presented in Table 5. Such good crystallographic agreement suggests that alloying with Re, which brings a hardening effect, should not cause complications associated with internal stresses. This also means that the positive effect of Re alloying can be exploited in superalloys. 
Table 5. Orientation ratios between the crystal lattice of the $\gamma^{\prime}$-phase and the crystal lattices of the secondary phases in various states of the alloy.

\begin{tabular}{cccc}
\hline \multirow{2}{*}{ State of the Alloy } & \multicolumn{3}{c}{ Secondary Phase } \\
\cline { 2 - 4 } & $\boldsymbol{\beta}$-Phase & $\chi$-Phase & $\boldsymbol{\sigma}$-Phase \\
\hline After DC & {$[110]_{\beta} I I[111]_{\gamma^{\prime}}$} & {$[32 \overline{3}]_{\chi} I I[001]_{\gamma^{\prime}}$} & - \\
\hline After DC and annealing & - & - & {$[100]_{\sigma} I I[11 \overline{1}]_{\gamma^{\prime}}$} \\
\hline
\end{tabular}

\subsection{Sizes of Quasi-Cuboids, Secondary Phases, and Dislocation Structure}

As noted above, in alloys both after DC and after DC and subsequent annealing, there are areas with ideal (undamaged) quasi-cuboids of the $\gamma^{\prime}$-phase. A schematic representation of such quasi-cuboids and their sizes are shown in Figure 8 and Table 6, respectively. As can be seen in Table 6, the sizes of quasi-cuboids in the alloy after DC are the smallest.

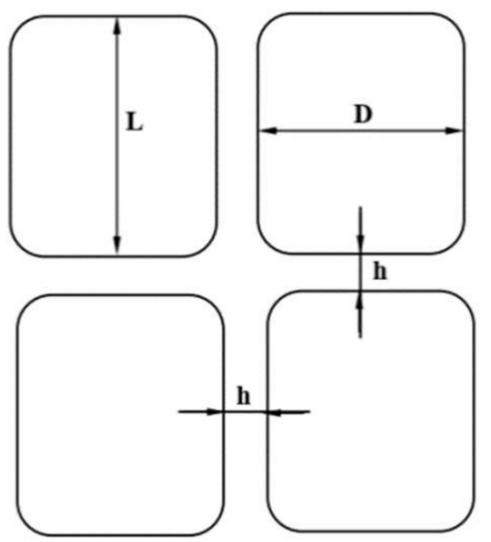

Figure 8. Schematic representation of quasi-cuboids: D—transverse; L-longitudinal size of $\gamma^{\prime}$-phase quasi-cuboids; $h$ is the width of the $\gamma$-phase interlayers.

Table 6. Quantitative properties of quasi-cuboids of the $\gamma / \gamma^{\prime}$ mixture.

\begin{tabular}{|c|c|c|c|c|c|}
\hline \multirow[b]{2}{*}{ The State of the Alloy } & \multicolumn{2}{|c|}{ The Sizes of Quasi-Cuboids of $\gamma^{\prime}$-Phase } & \multirow{2}{*}{$\begin{array}{l}\text { The Width of } \gamma \text {-Phase } \\
\text { Interlayers, } h, n m\end{array}$} & \multicolumn{2}{|c|}{$\begin{array}{l}\text { Scalar Dislocation Density, } \\
\rho \cdot 10^{-10}, \mathrm{~cm}^{-2}\end{array}$} \\
\hline & $\begin{array}{c}\text { Lateral Size, D, } \\
\mu \mathrm{m}\end{array}$ & $\begin{array}{c}\text { Longitudinal Size, } \\
\mathrm{L}, \mu \mathrm{m}\end{array}$ & & $\begin{array}{c}\text { in } \gamma^{\prime} \text {-Phase, } \\
\rho_{\gamma^{\prime \prime}} \\
\end{array}$ & $\begin{array}{c}\text { in } \gamma \text {-Phase, } \\
\rho_{\gamma} \\
\end{array}$ \\
\hline After DC & 0.32 & 0.44 & 80 & 3.8 & 8.8 \\
\hline After DC+annealing & 1.44 & 1.72 & 170 & 3.0 & 8.3 \\
\hline
\end{tabular}

In the alloy after DC and subsequent annealing, the dimensions of the quasi-cuboids of the $\gamma^{\prime}$-phase (D and L), as well as the width of the interlayers (h), increase, and the dimensions (D) grow faster than $\mathrm{h}$. The fact that the dimensions change disproportionately is due to two factors. The first is the different volume fraction of the $\gamma$ - and $\gamma^{\prime}$-phases. Secondly, there is a different volume fraction of ideal quasi-cuboids in each state of the alloy. Thirdly, the thickness of the $\gamma$-phase interlayers is nanometric, and the dimensions of the quasi-cuboids of the $\gamma^{\prime}$-phase in the state after DC are also nanometric; in the sample after annealing, they are a few micrometers. In turn, the volume fraction of the distorted $\gamma / \gamma^{\prime}$ structure is due to the formation of various secondary phases $(\beta, \chi, \sigma)$ in it and the kinetics of this process.

The particle sizes of the secondary phases (see Tables 2 and 3) range from nanometric to microns. This means that a significant role in the formation of the superalloy properties will be played by particles periodically located in groups in the bulk of the superalloy 
material and belonging to the areas where the damaged $\gamma / \gamma^{\prime}$ mixture and secondary phases are located.

\subsection{Scalar Dislocation Density $(\rho)$}

The average values of the scalar dislocation densities in the $\gamma^{\prime}$ - and $\gamma$-phases are given in Table 6. As follows from Table 6, in the $\gamma$-phase, the value of $\rho$ is much larger than in the $\gamma^{\prime}$-phase. Annealing the alloy at a high temperature decreases the $\rho$ value in both phases. This indicates a high degree of dislocation pinning in both phases of the superalloy. This is especially true for super-dislocations in the ordered $\gamma^{\prime}$-phase.

The dislocation structure in the $\gamma^{\prime}$-phase is cellular-meshy. In the $\gamma$-phase, it is not possible to classify the structure, since it is fixed in narrow channels.

\subsection{Phase Transformations during Alloy Annealing after DC}

As stated above, after high-temperature annealing of the DC alloy, a phase transformation occurs. Let us compare the phase composition and the volume fraction of the alloy phases in these two states (Table 7).

Table 7. Quantitative phase compositions of alloys.

\begin{tabular}{ccccc}
\hline The State of the Alloy & $\begin{array}{c}\text { The Volume Fraction } \\
\text { of Ideal } \boldsymbol{\gamma}^{\prime} \text {-Phase, } \%\end{array}$ & $\begin{array}{c}\text { The Volume Fraction of } \\
\text { Damaged Mixture } \boldsymbol{\gamma} / \boldsymbol{\gamma}^{\prime}, \boldsymbol{\%}\end{array}$ & $\begin{array}{c}\text { The Volume Fraction } \\
\text { of } \boldsymbol{\beta} \text {-Phase, } \%\end{array}$ & $\begin{array}{c}\text { Phases before and } \\
\text { after Transformation }\end{array}$ \\
\hline After DC & 65 & 30 & - & $\beta+\chi$ \\
\hline After DC and annealing & 90 & 10 & 5 & $\sigma$ \\
\hline
\end{tabular}

It is quite obvious that the phase transformation is complex. It was found that it occurs, first, in the interlayers of the $\gamma$-phase of the imperfect part of the structure; secondly, inside $\gamma^{\prime}$-quasi-cuboids of the same part of the structure; thirdly, in the free space between areas with quasi-cuboids. A part of the area of the damaged quasi-cuboids and the $\beta$-phase transforms into an ideal zone of quasi-cuboids. The following transformation occurs: $\left[\left(\gamma^{\prime}+\gamma\right)\right.$ partially $+(\beta+\gamma)$ completely $] \rightarrow\left(\gamma+\gamma^{\prime}+\sigma\right)$. This transformation is of a diffusion nature and is connected with mass transfer. It is mainly localized in the areas of the $\beta$-phase and the damaged $\gamma / \gamma^{\prime}$ mixture. The volume fraction of the $\gamma$-phase is generally preserved, and the $\gamma^{\prime}$-phase even slightly increases. Apparently, this occurs due to the decomposition of the $\beta$-phase. In this case, some $\mathrm{Al}$ atoms pass into the $\sigma$-phase. Re atoms from the $\beta$-phase also pass into the $\sigma$-phase. The atoms of $\mathrm{Re}, \mathrm{Co}, \mathrm{Mo}, \mathrm{W}$, and $\mathrm{Al}$ leave the $\chi$ phase to form the $\sigma$ phase. $\mathrm{Cr}$ atoms are also added there. The diagrams of the equilibrium of Re with Mo, W, and other elements [25] show that at a close volume fraction of the $\sigma$ - and $\chi$-phases, the reaction is at quasi-equilibrium, and some of the elements from the $\beta$-phase also appear in the $\sigma$-phase.

\section{Conclusions}

The phase composition, morphology of the phases, and their localization in the bulk of the Ni-Al-Cr-Me superalloy doped with Re were studied with TEM and SEM methods. The volume fractions of the phases and the particle sizes of the phases were measured after directional crystallization (DC) and subsequent annealing.

During the research, the formation of refractory phases was established. These phases are $\beta-, \sigma_{-}$, and $\chi$-phases. The formation of these phases leads to hardening of the superalloy for the following reasons: First, the resulting phases are ordered; secondly, their morphological features, $\chi^{-}, \beta-$, and $\sigma$-phases, are shaped like needles or plates and contribute to barrier deceleration of dislocations; thirdly, the formation of phases $\beta, \sigma$, and $\chi$ led to the fact that the alloy became multiphase; fourthly, these phases, being refractory, increase the working temperature of the alloy.

The periodicity in the arrangement of spatial structures was established, where the ideal state of the $\gamma / \gamma^{\prime}$ mixture is interchanged with the strongly damaged one 
$\left(\gamma^{\prime}+\gamma+\right.$ secondary phases). There is no doubt that the periodic structure of the superalloy with a suitable orientation will help to strengthen the alloy. In other words, there are reserves at the mesoscale level for strengthening the superalloy material.

Author Contributions: N.A.K. directed the general research program; N.A.K., E.L.N., and N.A.P. conducted research and discussed the results; A.V.N. oversaw the software. All co-authors have contributed to the manuscript. All authors have read and agreed to the published version of the manuscript.

Funding: The research was carried out within the state assignment of the Ministry of Science and Higher Education of the Russian Federation (theme No. FEMN-2020-0004).

Conflicts of Interest: The authors declare no conflict of interest.

\section{References}

1. Stoloff, N.S.; Hagel, W.C. Superalloys II; Sims, C.T., Ed.; Wiley-Interscience Publication John Wiley \& Sons Publisher: Hoboken, NJ, USA, 1987; p. 615.

2. Sims, C.T.; Stoloff, N.S.; Hagel, W.C. Superalloys II: High-Temperature Materials for Aerospace and Industrial Power; Metallurgiya Publisher: Moscow, Russia, 1995; Volume 1, p. 385.

3. Reed, R. The Superalloys: Fundamental and Applications; Cambridge University Press: Cambridge, UK, $2006 ;$ p. 363.

4. Hausmann, D.; Solís, C.; Freund, L.P.; Volz, N.; Heinemann, A.; Göken, M.; Gilles, R.; Neumeier, S. Enhancing the HighTemperature Strength of a Co-Base Superalloy by Optimizing the $\gamma / \gamma^{\prime}$ Microstructure. Metals 2020, 10, 321. [CrossRef]

5. Smith, T.; Esser, B.; Antolin, N. Phase transformation strengthening of high-temperature superalloys. Nat. Commun. 2016, 7, 1-7. [CrossRef] [PubMed]

6. Parsa, A.B.; Wollgramm, P.; Buck, H.; Somsen, C.; Kostka, A.; Povstugar, I.; Choi, P.; Raabe, D.; Dlouhy, A.; Müller, J. Advanced Scale Bridging Microstructure Analysis of Single Crystal Ni- Base Superalloys. Adv. Eng. Mater. 2014, 17, 216-230. [CrossRef]

7. Viswanathan, G.; Shi, R.; Genc, A.; Vorontsov, V.; Kovarik, L.; Rae, C. Segregation at stacking faults within the $\gamma^{\prime}$ phase of two Ni-base superalloys following intermediate temperature creep. Scr. Mater. 2015, 94, 5-8. [CrossRef]

8. Agudo Jácome, L.; Nörtershäuser, P.; Somsen, C.; Dlouhý, A.; Eggeler, G. On the nature of $\gamma^{\prime}$ phase cutting and its effect on high temperature and low stress creep anisotropy of Nibase single crystal superalloys. Acta Mater. 2014, 69, 246-264. [CrossRef]

9. Krutz, N.; Shen, C.; Karadge, M.; Egan, A.J.; Bennett, J.R.; Hanlon, T.; Mills, M.J. An Approach Toward Understanding Unstable Gamma Prime Precipitate Evolution and Its Effect on Properties. In Superalloys 2020, The Minerals, Metals E Materials Series; Tin, S., Hardy, M., Clews, J., Cormier, J., Feng, Q., Marcin, J., O’Brien, C., Suzuki, A., Eds.; Springer: Beijing, China, 2020 ; pp. 691-701.

10. Kuznetsov, V.P.; Lesnikov, V.P.; Popov, N.A.; Vasil'ev, A.S.; Popova, E.N. Phase Transformations in Single-Crystal Refractory Nickel Alloy with Tantalum, Rhenium and Ruthenium Additions. Metal Sci. Heat Treat. 2018, 60, 100-105. [CrossRef]

11. Kozlov, E.V.; Nikonenko, E.L.; Popova, N.A.; Koneva, N.A. Structure and composition of higherrhenium-content superalloy based on La-alloyed Ni-Al-Cr. AIP Conf. Proc. 2015, 1683, 020101.

12. Pollock, T.M. Alloy design for aircraft engines. Nat. Mater. 2016, 15, 809-815. [CrossRef] [PubMed]

13. Almirall, N.; Wells, P.; Yamamoto, T. Precipitation and hardening in irradiated low alloy steels with a wide range of Ni and Mn compositions. Acta Mater. 2019, 179, 119-128. [CrossRef]

14. Sun, W.; Zhu, Y.; Marceau, R. Precipitation strengthening of aluminum alloys by room-temperature cyclic plasticity. Science 2019, 2019, 972-975. [CrossRef] [PubMed]

15. Wang, Z.; Zhang, L.; Li, W. High throughput experiment assisted discovery of new Ni-base superalloys. Scr. Mater. 2020, 178, 134-138. [CrossRef]

16. Barba, D.; Alabort, E.; Pedrazzini, S.; Collins, D.M.; Wilkinson, A.J.; Bagot, P.A.J.; Moody, M.P.; Atkinson, C.; Jérusalem, A.; Reed, R.C. On the microtwinning mechanism in a single crystal superalloy. Acta Mater. 2017, 135, 314-329. [CrossRef]

17. Seiser, B.; Drautz, R.; Pettifor, D. TCP phase predictions in Ni-based superalloys: Structure maps revisited. Acta Mater. 2011, 59, 749-763. [CrossRef]

18. Rae, C.M.; Reed, R.C. The precipitation of topologically close-packed phases in rhenium-containing superalloys. Acta Mater. 2001, 49, 4113-4125. [CrossRef]

19. Kolobov, Y.R.; Kablov, E.N.; Kozlov, E.V. Structure and Properties of Intermetallic Materials with Nano-Phase Hardening; MISiS: Moscow, Russia, 2008; p. 328.

20. Kozlov, E.V.; Smirnov, A.N.; Nikonenko, E.L.; Popova, N.A.; Koneva, N.A. Phase Morphology and Transformations due to Thermal Treatment of Ni-Al-Cri Ni-Al-Co-based Superalloys. Scale and Concentration Effects; Innovatsionnoe mashinostroenie: Moscow, Russia, 2016; p. 175.

21. Blavette, D.; Caron, P.; Khan, T. An atom probe investigation of the role of rhenium additions in improving creep resistance of Ni-base superalloys. Scr. Metall. 1986, 20, 1395-1400. [CrossRef]

22. Mottura, A.; Reed, R.C. What is the role of rhenium in single crystal superalloys? MATEC Web Conf. 2014, 14, 1-6. [CrossRef]

23. Kozlov, E.V.; Nikonenko, E.L.; Koneva, N.A.; Popova, N.A. Effect of Re Content on Structure and Phase Composition of Ni-Al Alloys. Bull. Russ. Acad. Sci. Phys. 2005, 69, 1116-1120. 
24. Kozlov, E.V.; Popova, N.A.; Kabanina, O.V.; Klimashin, S.I.; Gromov, V.E. The Evolution of Phases State, Defect Structure, Internal Stresses and Redistribution of Carbon and Temper of Cast Structural Steel; Izdatel'stvo SibGIU: Novokuznetsk, Russia, 2007 ; p. 177.

25. Saltykov, S.A. Stereometric Metallography; Metallurgy: Moscow, Russia, 1976; p. 271.

26. Hirsch, P.; Howie, A.; Nicholson, R. Electron Microscopy of Thin Crystals; Mir: Moscow, Russia, 1968 ; p. 574.

27. Lyakishev, N.P. Diagrams of Binary Metal Systems; Mechanical engineering: Moscow, Russia, 1996-2000; pp. 1-3.

28. Cornish, L.A.; Witcomb, M.J. A metallographic study of the Al-Ni-Re phase diagram. J. Alloys Comp. 1999, 291, 145-166. [CrossRef] 